\title{
Chronic Intra-Uterine Ureaplasma parvum Infection Induces Injury of the Enteric Nervous System in Ovine Fetuses
}

Cathelijne Heymans ${ }^{1}$, Ilse H. de Lange ${ }^{1,2}$, Matthias C. Hütten ${ }^{2,3,4,5}$, Kaatje Lenaerts ${ }^{1}$, Nadine J. E. de Ruijter ${ }^{2}$, Lilian C. G. A. Kessels ${ }^{2}$, Glenn Rademakers ${ }^{6}$, Veerle Melotte ${ }^{6}$, Werend Boesmans ${ }^{6,7}$, Masatoshi Saito ${ }^{8,9}$, Haruo Usuda ${ }^{8,9}$, Sarah J. Stock ${ }^{10}$, Owen B. Spiller ${ }^{11}$, Michael L. Beeton ${ }^{12}$, Matthew S. Payne ${ }^{8}$, Boris W. Kramer ${ }^{2,3}$, John P. Newnham ${ }^{8}$, Alan H. Jobe ${ }^{8,13}$, Matthew W. Kemp ${ }^{8,9,14}$, Wim G. van Gemert ${ }^{1,15,16}$ and Tim G. A. M. Wolfs ${ }^{2,17 *}$

\section{OPEN ACCESS}

Edited by:

Per T. Sangild,

University of Copenhagen, Denmark

Reviewed by:

David Hackam,

Johns Hopkins Medicine,

United States

Jacqueline Cheuk-Yan Lai,

University of Gothenburg, Sweden

*Correspondence:

Tim G. A. M. Wolfs

tim.wolfs@maastrichtuniversity.nl

Specialty section:

This article was submitted to Microbial Immunology,

a section of the journal

Frontiers in Immunology

Received: 13 November 2019

Accepted: 24 January 2020

Published: 17 March 2020

Citation:

Heymans $C$, de Lange IH, Hütten $M C$,

Lenaerts K, de Ruijter NJE,

Kessels LCGA, Rademakers G, Melotte V, Boesmans W, Saito M,

Usuda H, Stock SJ, Spiller OB, Beeton ML, Payne MS, Kramer BW, Newnham JP, Jobe AH, Kemp MW,

van Gemert WG and Wolfs TGAM

(2020) Chronic Intra-Uterine

Ureaplasma parvum Infection Induces Injury of the Enteric Nervous System in Ovine Fetuses.

Front. Immunol. 11:189. doi: 10.3389/fimmu.2020.00189
${ }^{1}$ Department of Surgery, NUTRIM School of Nutrition and Translational Research in Metabolism, Maastricht University, Maastricht, Netherlands, ${ }^{2}$ Department of Pediatrics, School for Oncology and Developmental Biology (GROW), Maastricht University, Maastricht, Netherlands, ${ }^{3}$ Neonatology, Department of Pediatrics, Maastricht University Medical Center, Maastricht, Netherlands, ${ }^{4}$ Neonatology, Department of Pediatrics, University Hospital Aachen, Aachen, Germany, ${ }^{5}$ Neonatology, Department of Pediatrics, University Children's Hospital Würzburg, Würzburg, Germany, ${ }^{6}$ Department of Pathology, School for Oncology and Developmental Biology (GROW), Maastricht University Medical Center, Maastricht, Netherlands, ${ }^{7}$ Biomedical Research Institute (BIOMED), Hasselt University, Hasselt, Belgium, ${ }^{8}$ Division of Obstetrics and Gynecology, University of Western Australia, Perth, WA, Australia, ${ }^{9}$ Center for Perinatal and Neonatal Medicine, Tohoku University Hospital, Sendai, Japan, ${ }^{10}$ Usher Institute, University of Edinburgh, Edinburgh, United Kingdom, ${ }^{11}$ Division of Infection and Immunity, School of Medicine, Cardiff University, Cardiff, United Kingdom, ${ }^{12}$ Cardiff School of Sport and Health Sciences, Cardiff Metropolitan University, Cardiff, United Kingdom, ${ }^{13}$ Division of Neonatology/Pulmonary Biology, The Perinatal Institute, Cincinnati Children's Hospital Medical Center, University of Cincinnati, Cincinnati, OH, United States, ${ }^{14}$ School of Veterinary and Life Sciences, Murdoch University, Perth, WA, Australia, ${ }^{15}$ Pediatric Surgery, Department of Surgery, Maastricht University Medical Center, Maastricht, Netherlands, ${ }^{16}$ Department of Surgery, University Hospital Aachen, Aachen, Germany, ${ }^{17}$ Department of Biomedical Engineering (BMT), School for Cardiovascular Diseases (CARIM), Maastricht University, Maastricht, Netherlands

Background: Chorioamnionitis, inflammation of the fetal membranes during pregnancy, is often caused by intra-amniotic (IA) infection with single or multiple microbes. Chorioamnionitis can be either acute or chronic and is associated with adverse postnatal outcomes of the intestine, including necrotizing enterocolitis (NEC). Neonates with NEC have structural and functional damage to the intestinal mucosa and the enteric nervous system (ENS), with loss of enteric neurons and glial cells. Yet, the impact of acute, chronic, or repetitive antenatal inflammatory stimuli on the development of the intestinal mucosa and ENS has not been studied. The aim of this study was therefore to investigate the effect of acute, chronic, and repetitive microbial exposure on the intestinal mucosa, submucosa and ENS in premature lambs.

Materials and Methods: A sheep model of pregnancy was used in which the ileal mucosa, submucosa, and ENS were assessed following IA exposure to lipopolysaccharide (LPS) for 2 or 7 days (acute), Ureaplasma parvum (UP) for 42 days (chronic), or repetitive microbial exposure (42 days UP with 2 or 7 days LPS).

Results: IA LPS exposure for 7 days or IA UP exposure for 42 days caused intestinal injury and inflammation in the mucosal and submucosal layers of the gut. Repetitive microbial exposure did not further aggravate injury of the terminal ileum. Chronic IA UP exposure caused significant structural ENS alterations characterized by loss of PGP9.5 
and $S 100 \beta$ immunoreactivity, whereas these changes were not found after re-exposure of chronic UP-exposed fetuses to LPS for 2 or 7 days.

\begin{abstract}
Conclusion: The in utero loss of PGP9.5 and S100 $\beta$ immunoreactivity following chronic UP exposure corresponds with intestinal changes in neonates with NEC and may therefore form a novel mechanistic explanation for the association of chorioamnionitis and NEC.
\end{abstract}

Keywords: Ureaplasma parvum, intra-amniotic infection, chorioamnionitis, enteric nervous system, sheep, preterm birth, necrotizing enterocolitis

\section{INTRODUCTION}

Preterm birth is a common and major worldwide health issue, contributing to significant neonatal morbidity and mortality (1). Around 1 in every 10 births are preterm, accounting for $\sim 15$ million premature newborns each year (2). Due to complications, over one million premature newborns will die shortly after birth $(3,4)$. Chorioamnionitis, defined as inflammatory cell infiltration of fetal membranes, is frequently associated with preterm birth and typically occurs due to an ascending bacterial infection (5-7) that can be acute or chronic (8). Intrauterine exposure of preterm infants to chorioamnionitis is associated with an increased risk of adverse neonatal outcomes $(9,10)$, including necrotizing enterocolitis (NEC) $(9,11,12)$. Adverse gastrointestinal outcomes have been associated with both systemic fetal inflammatory response syndrome (FIRS) and direct exposure of the gut to the swallowed infected amniotic fluid $(11,13,14)$. Chorioamnionitis can occur with intact membranes, which is common for genital mycoplasmas, such as Ureaplasma species (spp.), present in the lower genital tract of women $(6,15)$. Ureaplasma spp. can cause chronic chorioamnionitis that does not evoke a maternal response, but is still associated with adverse fetal outcomes (16). In an experimental large animal model, we previously showed that a Ureaplasma parvum (UP) serovar 3 infection up to 14 days prior to delivery causes fetal gut inflammation with damaged villus epithelium, gut barrier loss, and severe villus atrophy (17).

The injury caused by intrauterine Ureaplasma spp. exposure might derive from the direct inflammatory reaction, as well as from potential interactions with other inflammatory stimuli. Chorioamnionitis is often polymicrobial, as over $65 \%$ of positive amniotic fluid cultures lead to the identification of two or more pathogens (7). In this context, we previously showed that cerebral and lung immune activation following intra-amniotic (IA)

Abbreviations: AU, Arbitrary unit; BSA, Bovine serum albumin; CD3, Cluster of differentiation 3; CCU, Color-changing units; CHAT, Choline acetyltransferase; ENS, Enteric nervous system; FCS, Fetal calf serum; FIRS, Fetal inflammatory response syndrome; GAPDH, Glyceraldehyde 3-phosphate dehydrogenase; GFAP, Glial fibrillary acidic protein; IA, Intra-amniotic; IBD, Inflammatory bowel disease; IL, Interleukin; IRAK3, Interleukin-1 receptorassociated kinase 3; LPS, Lipopolysaccharide; MPO, Myeloperoxidase; NEC, Necrotizing enterocolitis; NGS, Normal goat serum; $n N O S$, Neuronal nitric oxide synthase; PBS, Phosphorylated buffer saline; PGP9.5, Protein gene product 9.5; PPIA, Peptidylprolyl isomerase A; RPS15, Ribosomal protein S15; Spp, Species; $T L R$, Toll-like receptor; TNF- $\alpha$, Tumor necrosis factor alpha; UP, Ureaplasma parvum. lipopolysaccharide (LPS) exposure was prevented when these animals were chronically pre-exposed to UP serovar $3(18,19)$. This illustrates that interactions between different microbes can occur, leading to organ-specific sensitization or preconditioning.

The enteric nervous system (ENS) consists of enteric neurons and glial cells, autonomously regulates gastrointestinal activity (i.e., secretion, absorption, and motility), and contributes to gut integrity (20). The formation of the ENS requires coordinated migration, proliferation, and differentiation of neural crest progenitors, directed neurite growth, and establishment of a network of interconnected neurons and glia $(21,22)$. Although these processes mostly occur in utero, an important part of ENS development takes place postnatally $(23,24)$. Neonates with NEC have structural and functional damage of the submucosal and myenteric plexus, including loss of enteric neurons and glial cells (25-27). The involvement of chorioamnionitis in the induction of adverse intestinal outcomes including NEC, combined with the presence of ENS abnormalities in NEC, prompted us to study the impact of an antenatal infection on the ENS.

The aim of this study was therefore to investigate the effect of acute IA exposure to LPS and chronic exposure to UP on the intestinal mucosa and ENS in fetal lambs using a well-established sheep model of chorioamnionitis. In addition, we investigated the potential interactions of repetitive IA microbial stimuli by acute exposure to LPS in ovine fetuses that were chronically pre-exposed to UP.

\section{MATERIALS AND METHODS Animal Model and Experimental Procedures}

All experiments were approved by the animal ethics committee of the University of Western Australia (Perth, Australia).

The animal model and experimental procedures were previously described (18). Briefly, 39 date-mated merino ewes were randomly assigned to six different groups of between five and eight animals to receive IA injections under ultrasound guidance. Verification of the IA injections was done by amniotic fluid electrolyte analysis. The date-mated pregnant ewes received an IA injection of an in vitro cultured strain HPA5 of UP serovar $3\left(2 \times 10^{5}\right.$ color-changing units, CCU) (28) 42 days prior to delivery (at 82 days of gestation, which corresponds to the second trimester in humans) or Escherichia coli-derived LPS (O55:B5; Merck, Darmstadt, Germany), $10 \mathrm{mg}$ in $2 \mathrm{ml}$ of saline, 2 or 7 days prior to delivery (at respectively, 122 and 117 days of gestation). 
Previously, we have shown that the half-life time of LPS in the amniotic fluid is relatively long (1.7 days) and that the LPS amount is higher than the essential threshold of $1 \mathrm{mg}$ for at least 5 days $(29,30)$. Chronic sustained UP infection was confirmed by positive culture of amniocentesis samples at intermediate time points and sterile amniotic fluid samples collected at cesarean delivery, as previously described (31). Two or seven days LPS exposure (prior to cesarean delivery) represents an acute inflammatory challenge. To evaluate the combined effect between these inflammatory modalities, a subgroup of chronically UPinfected ewes received IA LPS at 35 and 40 days post-UP infection (i.e., 7 or 2 days LPS exposure prior to delivery following 42 days of UP infection). A group receiving IA injections of sterile saline ( 2 or 7 days prior to delivery, respectively six and two animals which were pooled) served as controls (Figure 1). Fetuses were surgically delivered at $124 \pm 2$ days of gestational age (term gestation in sheep $=150$ days), equivalent of $\sim 30$ weeks of human gestation. After delivery, fetuses were euthanized with intravenous pentobarbitone $(100 \mathrm{mg} / \mathrm{kg})$. For this experiment, fetuses of both sexes were used.

\section{Sampling}

During necropsy, blood and terminal ileum samples were collected. Ileum samples were fixed in $10 \%$ formalin and embedded in paraffin, or snap frozen in liquid nitrogen. Where insufficient paraffin-embedded material was available for study, additional material was generated by paraffin embedding snapfrozen tissue samples: frozen tissue blocks were defrosted, fixed in $4 \%$ formaldehyde at room temperature overnight, and transferred to $70 \%$ ethanol prior to embedding in paraffin with the use of a vacuum infiltration processor.

\section{Antibodies}

The following antibodies were used for immunohistochemistry: polyclonal rabbit anti-myeloperoxidase (MPO; A0398, Dakocytomation, Glostrup, Denmark) for the identification of neutrophils, polyclonal rabbit anti-cluster of differentiation 3 (CD3; A0452, Dakocytomation) for the detection of $\mathrm{T}$ cells, polyclonal rabbit anti-bovine protein gene product 9.5 (PGP9.5; Z5116, Dakocytomation) for the detection of enteric neurons, polyclonal rabbit anti-doublecortin (Ab18723, Abcam, Cambridge, UK) for the detection of immature neurons, polyclonal rabbit anti-glial fibrillary acidic protein (GFAP; Zo334, Dakocytomation) to detect enteric glial cell reactivity/activation (32), and polyclonal rabbit anti-S100 $\beta$ (PA5-16257, Invitrogen, Carlsbad, CA, USA) as a marker for enteric glial cells.

The following secondary antibodies were used: peroxidaseconjugated polyclonal goat anti-rabbit (111-035-045, Jackson, West Grove, PA, USA) (MPO), peroxidase-conjugated polyclonal swine anti-rabbit (P0399, DakoCytomation) (doublecortin) and BrightVision+ Poly-HRP-Anti Mouse/Rabbit IgG biotin-free (ImmunoLogic, Duiven, Netherlands) (PGP9.5), and biotin-conjugated polyclonal swine anti-rabbit (E0353, DakoCytomation) (CD3, GFAP, S100 $\beta$ ).

\section{Immunohistochemistry}

Formalin-fixed terminal ileum was embedded in paraffin and $4 \mu \mathrm{m}$ sections were cut. After deparaffinization and rehydration, endogenous peroxidase activity was blocked with $0.3 \% \mathrm{H}_{2} \mathrm{O}_{2}$ diluted in phosphorylated buffer saline (PBS, pH 7.4). Antigen retrieval was performed with citrate buffer for CD3, PGP9.5, doublecortin, and S100 $\beta$ stainings. Non-specific binding was blocked for $30 \mathrm{~min}$ at room temperature with $10 \%$ normal goat serum (NGS) in PBS (MPO), 5\% NGS in PBS (doublecortin), or $5 \%$ bovine serum albumin (BSA) in PBS (CD3, GFAP, and $\mathrm{S} 100 \beta$ ). For PGP9.5, non-specific binding was blocked for $10 \mathrm{~min}$ at room temperature with $20 \%$ fetal calf serum (FCS). Thereafter, sections were incubated with the primary antibody of interest and subsequently incubated with the respective secondary antibody. MPO, PGP9.5, and doublecortin were detected by using a peroxidase-conjugated secondary antibody and antibodies against CD3, GFAP, and $S 100 \beta$ were detected with

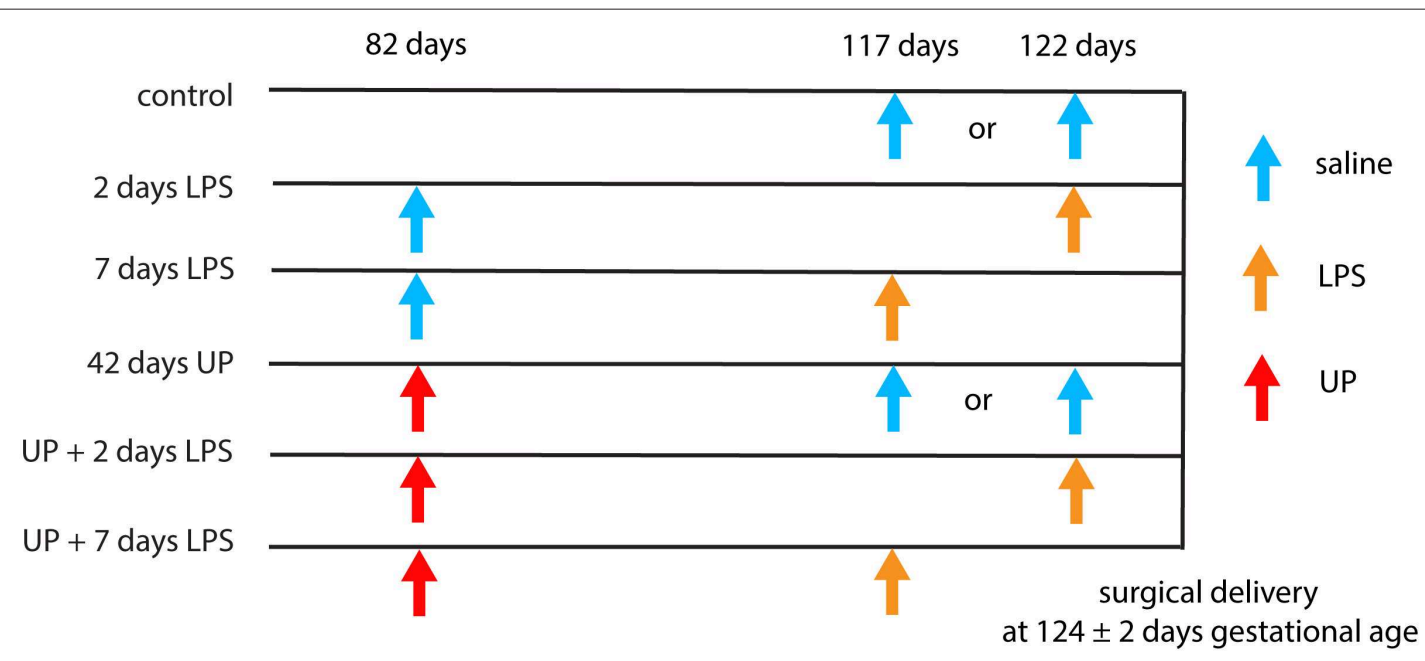

FIGURE 1 | Different intervention study groups. All injections were delivered by ultrasound-guided amniocentesis. Timing is shown in gestational days. 
TABLE 1 | Primer sequences.

\begin{tabular}{|c|c|c|}
\hline Primer & Forward & Reverse \\
\hline RPS15 & 5'-CGAGATGGTGGGCAGCAT-3' & 5'-GCTTGATITCCACCTGGTTGA-3' \\
\hline GAPDH & 5'-GGAAGCTCACTGGCATGGC-3' & 5'-CCTGCTTCACCACCTTCTTG-3' \\
\hline PPIA & 5'-TTATAAAGGTTCCTGCTITCACAGAA-3' & 5'-ATGGACTTGCCACCAGTACCA-3' \\
\hline $\mathrm{IL}-1 \beta$ & 5'-AGAATGAGCTGTTATITGAGGTTGATG-3' & 5'-GTGAGAAATCTGCAGCTGGATGT-3' \\
\hline IL-6 & 5'-ACATCGTCGACAAAATCTCTGCAA-3' & 5'-GCCAGTGTCTCCTTGCTGTI-3' \\
\hline IL-10 & 5'-CATGGGCCTGACATCAAGGA-3' & 5'-CGGAGGGTCTTCAGCTTCTC-3' \\
\hline TNF- $\alpha$ & 5'-GCCGGAATACCTGGACTATGC-3' & 5'-CAGGGCGATGATCCCAAAGTAG-3' \\
\hline IRAK3 & 5'-AGTGTGTAGGTAACACAGCCC-3' & 5'-TGCTGGTCATGCTTATGGCA-3' \\
\hline nNOS & 5'-CGGCTITGGGGGTTATCAGT-3' & 5'-TTGССССАТTСССАСТССТС-3' \\
\hline CHAT & 5'-CCGCTGGTATGACAAGTCCC-3' & 5'-GCTGGTCTTCACCATGTGCT-3' \\
\hline
\end{tabular}

avidin-biotin complex (Vectastain Elite ABC kit, Bio-connect, Huissen, Netherlands). Substrate staining was performed for MPO with 3-amino-9-ethylcarbazole (AEC; Merck, Darmstadt, Germany). Immunoreactivity for CD3 and GFAP was detected by using nickel-DAB. Immunoreactivity for PGP9.5, doublecortin, and $S 100 \beta$ was detected by using DAB. Hematoxylin (MPO, PGP9.5, doublecortin, and S100 $\beta$ ) or nuclear fast red (CD3 and GFAP) was used as a counterstain for nuclei.

\section{Qualitative Analysis of Damage of the Terminal lleum}

$\mathrm{H} \& \mathrm{E}$ slides were analyzed by two independent investigators blinded to the experimental setup to assess damage of the terminal ileum. A scoring system from 0 to 4 was used to describe the severity of histological injury. Scoring was as follows: 0 , no damage; 1 , disrupted epithelial lining, but no loss of enterocytes; 2, disrupted epithelial lining, mild enterocyte loss from the villus tips; 3, disrupted epithelial lining, moderate enterocyte loss from villus tips, some debris in the lumen; and 4, abundant enterocyte loss from villus tips, abundant debris in the lumen, and severe shedding of villus tips.

\section{Quantification of Immunohistochemical Stainings}

The stained tissue sections were scanned with the Ventana iScan HT slide scanner (Ventana Medical Systems, Oro Valley, AZ, USA). Of these images, viewed with Panoramic Viewer (version 1.15.4, 3DHISTECH, Budapest, Hungary), random images of regions of interest were taken $(\times 200)$.

Two investigators blinded to the study groups counted the MPO- and CD3-positive cells in three to five non-overlapping high-power fields in the mucosa and submucosa. The average MPO- and CD3-positive cells per area are reported for each animal. The percentage of area in the submucosal and myenteric ganglia positively stained for PGP9.5, doublecortin, GFAP, and $\mathrm{S} 100 \beta$ was determined in five non-overlapping high-power fields using Leica QWin Pro software (version 3.4.0, Leica Microsystems, Mannheim, Germany) by an investigator blinded to the study groups. Relative area staining was calculated by dividing the positively stained areas of the ganglia of the submucosal or myenteric plexus by the total area of the muscle layer. The data are expressed as fold increase over the control value.

\section{RNA Extraction and Quantitative Real-Time PCR}

RNA was extracted from snap-frozen terminal ileum tissue using TRI reagent (Invitrogen)/chloroform extraction. Isolated RNA was DNase treated to remove possible contamination with genomic DNA by using the RQ1 RNase-Free DNase kit (Promega, Madison, WI, USA) and afterwards reverse transcribed into cDNA using oligo(dT)12-18 primers (Invitrogen) and Moloney murine leukemia virus (M-MLV) reverse transcriptase (Invitrogen). Quantitative real-time PCR (qPCR) reactions were performed with a LightCycler 480 Instrument (Roche Applied Science, Basel, Switzerland) using the SensiMix ${ }^{\mathrm{TM}} \mathrm{SYBR}^{\circledR}$ No-ROX kit (Bioline, London, UK) for 45 cycles. The mRNA levels of $I L-1 \beta, I L-6, I L-10$, tumor necrosis factor alpha $(T N F-\alpha)$, and interleukin-1 receptor-associated kinase 3 (IRAK3) were determined to assess inflammation of the terminal ileum. The mRNA levels of neuronal nitric oxide synthase ( $n N O S)$ and choline acetyltransferase (CHAT) were determined to assess the motility signaling functions of the ENS using LinRegPCR software (version 2016.0, Heart Failure Research Center, Academic Medical Center, Amsterdam, Netherlands). The geometric mean of the mRNA levels of three reference genes [ribosomal protein S15 (RPS15), glyceraldehyde 3-phosphate dehydrogenase $(G A P D H)$, and peptidylprolyl isomerase $\mathrm{A}(P P I A)]$ were calculated and used as a normalization factor. The data are expressed as fold increase over the control value. The primer sequences are shown in Table 1.

\section{Data Analysis}

Data are presented as median with interquartile range. Statistical analyses were performed using GraphPad Prism (version 6.01, GraphPad Software Inc., La Jolla, CA, USA). A non-parametric Kruskal-Wallis test followed by Dunn's post hoc test was used to analyze statistically significant group differences. Differences were considered statistically significant at $p<0.05$. Given the relatively small animal numbers per group, we also reported actual $p$ values between $p \geq 0.05$ and $p<0.10$ and interpreted these as potentially biologically relevant. This assumption will 


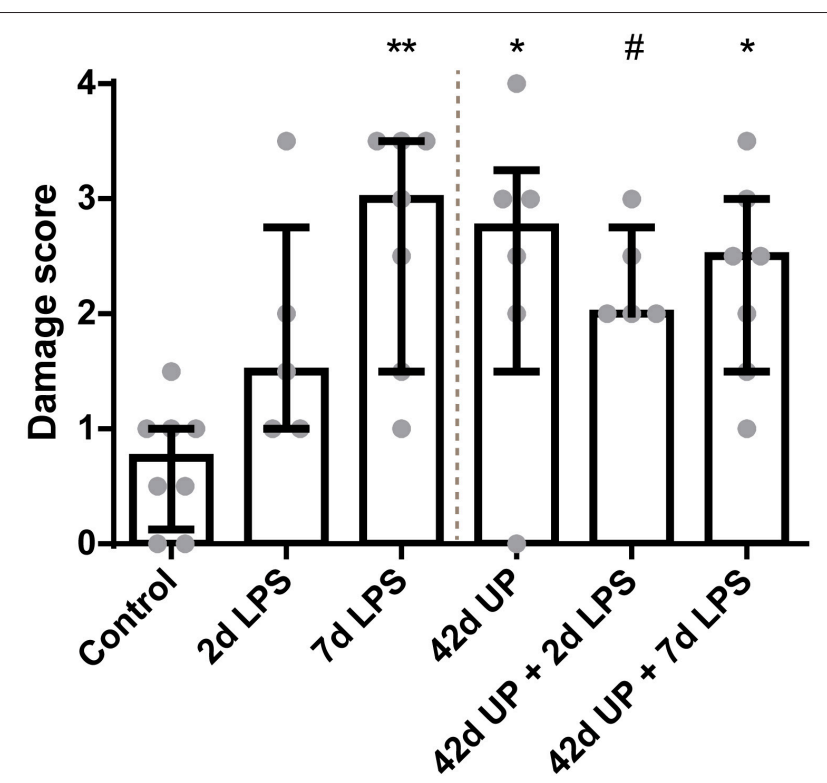

FIGURE 2 | Increased mucosal injury in all groups, except for the animals exposed to 2 days LPS. ${ }^{*} p=0.06,{ }^{*} p<0.05$, ${ }^{* *} p<0.005$ compared to the control.

decrease the chance of a type II error, but increases the chance of a type I error.

\section{RESULTS}

\section{Intestinal Damage and Inflammation in the Terminal lleum Due to Chorioamnionitis}

There was a higher intestinal damage score for all experimental groups compared to the control $(p<0.005$ for the 7 days LPS group, $p<0.05$ for the 42 days UP group and 42 days UP + 7 days LPS group, and $p=0.06$ for the 42 days UP +2 days LPS group all compared to the control; Figure 2), except for the animals exposed to 2 days of LPS. Pre-exposure with UP did not augment mucosal injury in the LPS-treated groups.

A statistically significant increase in MPO-positive cells was seen in the mucosa 7 days after LPS exposure compared to the control ( $p<0.05$; Figure 3). Chronic UP infection also caused an elevation of mucosal MPO-positive cells compared to the control ( $p=0.08$; Figure 3 ). Furthermore, combining these two inflammatory insults resulted in an increased mucosal MPO-positive cell count compared to the control $(p<0.005$; Figure 3), and this experimental group tended to be increased when compared to the UP +2 days LPS-exposed group $(p=0.07$; Figure 3). LPS exposure 2 days prior to delivery was insufficient to induce mucosal MPO-positive cell infiltration. Pre-exposure to UP in combination with LPS administration did not alter the number of mucosal MPO-positive cells compared to LPS alone, both after 2 and 7 days.

While chronic UP infection and acute LPS exposure 2 days pre-delivery did not have any effect on mucosal CD3-positive $\mathrm{T}$ cell presence, those animals receiving LPS 7 days pre-delivery (both uninfected and chronic UP-infected groups) as well as chronic UP-infected animals receiving LPS 2 days pre-delivery all showed apparent elevated levels of CD3-positive $\mathrm{T}$ cell infiltration (Figure 4). However, the only comparison to achieve $p<0.05$ significance was that of uninfected and chronic UPinfected animals receiving LPS 2 days pre-delivery (Figure 4).

For investigation of submucosal inflammation, there was an increase of MPO-positive cells in the 7 days LPS group and submucosal MPO-positive cells tended to be increased in the chronic UP infection group compared to the control $(p<0.05$ and $p=0.06$; Figure 5). Additional acute LPS insult ( 2 or 7 days pre-delivery) in chronic UP-infected animals resulted in increased variability and loss of significance in the MPO cell infiltration compared to 2 or 7 days of LPS alone.

The greatest increase of submucosal CD3-positive cells was observed in 2 day LPS-exposed chronic UP-infected animals, which was significantly increased compared to the control or acute 2 day LPS stimulation alone (both $p<0.05$; Figure 6) and appeared more potent than in chronic UP-infected animals receiving LPS at 7 days pre-delivery ( $p=0.08$; Figure 6).

Examination of underlying cytokine levels revealed increased $I L-1 \beta$ mRNA levels only in the uninfected or chronic UP-infected animals when LPS was administered 2 days pre-delivery $(p<$ 0.05 compared to the 7 days LPS group, $p<0.01$ compared to the 42 days UP group, $p<0.05$ compared to the 42 days $\mathrm{UP}+7$ days LPS group, and $p<0.05$ compared to the control, respectively; Figure 7A), whereas $I L-1 \beta$ mRNA levels had dropped to baseline again if LPS was administered 7 days pre-delivery (Figure 7A). $I L-6$ and $I L-10$ mRNA levels were not altered (data not shown), and the only group showing apparent TNF- $\alpha$ mRNA level elevation was that of the chronic UP-infected animals additionally receiving LPS 2 days pre-delivery $(p=0.07$; Figure 7B).

IRAK3 mRNA levels were increased significantly only in animals exposed to 2 days of LPS alone compared to the control $(p<0.05$; Figure 7C).

\section{ENS Alterations in the Terminal lleum Due to Chronic IA UP Exposure}

The PGP9.5-positive surface area in the submucosal plexus tended to be decreased in animals chronically infected for 42 days with UP compared to the control ( $p=0.08$; Figure 8). Similarly, chronic UP-infected animals had a diminished PGP9.5-positive surface area in the myenteric plexus ( $p<0.05$; Figure 8). Doublecortin-positive surface areas were not altered in either the submucosal or the myenteric plexus (data not shown).

In the submucosal plexus, the GFAP-positive surface area tended to be increased in groups receiving LPS either 2 or 7 days pre-delivery compared to the control $(p=0.07$ and $p=$ 0.09; Figure 9), while in the myenteric plexus, the GFAP-positive surface area was only increased in the group receiving LPS 7 days pre-delivery compared to the control ( $p<0.05$; Figure 9). For both of these regions, concomitant chronic infection by UP appeared to mute these effects.

S100 $\beta$-positive surface areas were unaltered in the submucosal plexus for all conditions (data not shown), while in the myenteric plexus, the S100 $\beta$-positive surface area was significantly 


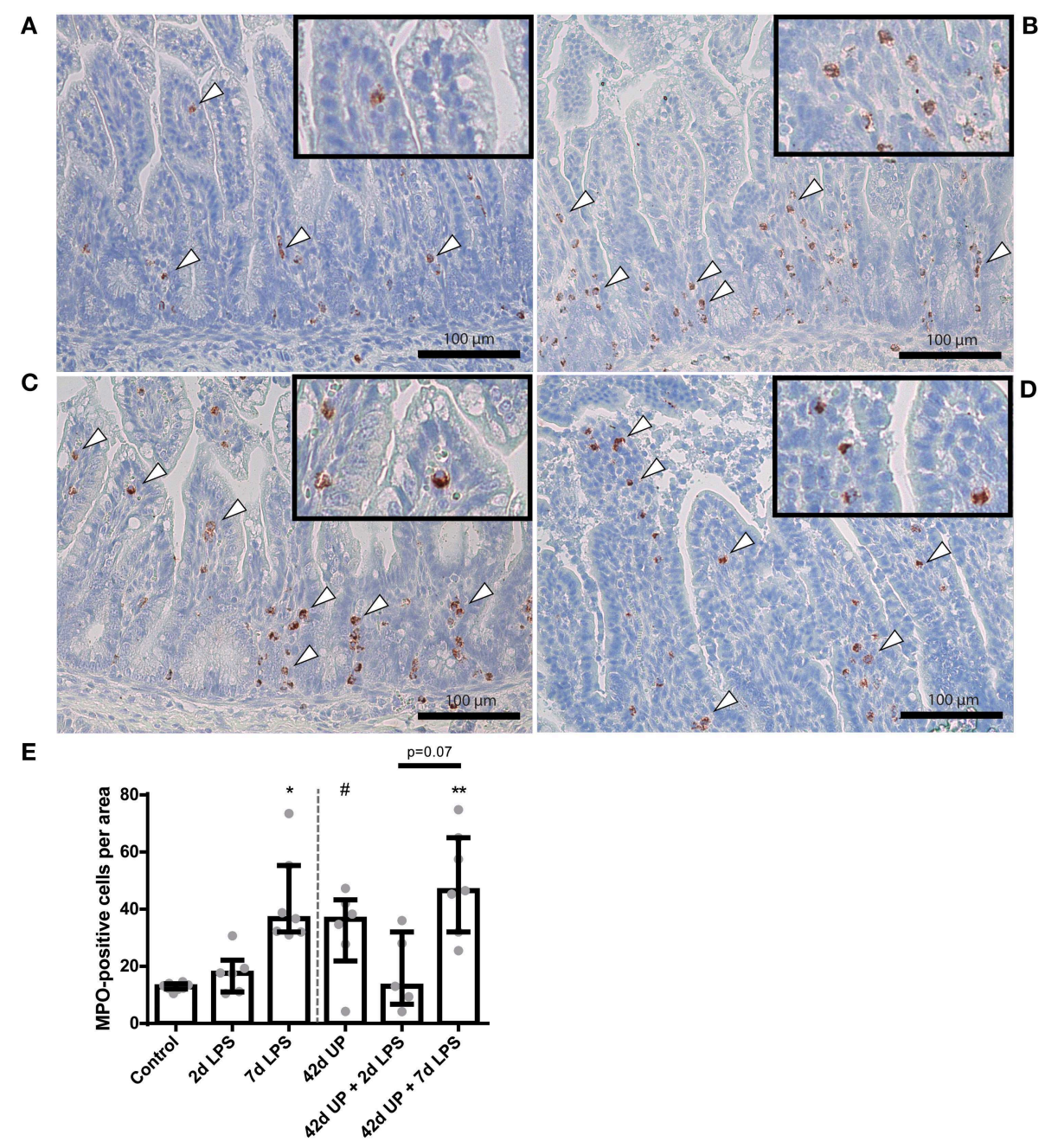

FIGURE 3 | Representative images of mucosal neutrophil influx reflected by myeloperoxidase (MPO)-positive cell (indicated by white triangles) counts of the control (A), 7 days lipopolysaccharide (LPS) (B), Ureaplasma parvum (UP) (C), and UP prior to 7 days LPS groups (D). (E) Increased MPO count in animals exposed to 7 days LPS, UP, and UP prior to 7 days LPS. ${ }^{*} p=0.08,{ }^{*} p<0.01,{ }^{* *} p<0.005$ compared to the control.

decreased in the chronic UP-infected group compared to the control ( $p<0.05$; Figure 10), but this effect appeared to be counteracted by acute stimulation by LPS at either 2 or 7 days pre-delivery. No differences in $n N O S$ and CHAT expression were observed between the groups (data not shown).

\section{DISCUSSION}

In this study, we investigated the effect of acute, chronic, and combined microbial exposure as an antenatal infectious trigger (chorioamnionitis) on the mucosa, submucosa, and ENS of the terminal ileum of premature lambs.

Both acute LPS and chronic UP exposure caused mucosal inflammation and injury to the terminal ileum. Although the inflammatory signature differed between these groups, mucosal injury was not aggravated in the combined exposure groups. Prenatal IA exposure to 7 days of LPS and to chronic 42 days infection by UP both provoked an influx of neutrophils (MPOpositive cells) in the intestine. In contrast, T cell (CD3-positive cells) numbers remained unaltered in the chronic UP and 2 days LPS groups compared to the control group, but were increased in the UP +2 days LPS-exposed animals, indicating a potential synergistic effect of both inflammatory stimuli in inducing an adaptive mucosal immune response. We observed a similar effect in the submucosa: while either LPS exposure or UP infection induced innate immune changes in the ileum, $\mathrm{T}$ cell alterations only occurred in the presence of combined UP and LPS exposure. Based on the current findings, we can only speculate on the mechanism behind this synergistic effect. In previous in vitro studies, signaling via Toll-like receptors (TLR) 1, 2, and 6 by Ureaplasma spp. increased LPS-mediated inflammation $(33,34)$. Additionally, TNF- $\alpha$ mRNA levels tended to be increased in the UP-infected animals receiving LPS 2 days pre-delivery, while $T N F-\alpha$ levels were not increased upon single exposure to either UP or LPS alone. In contrast, no synergistic effect of UP and 
A

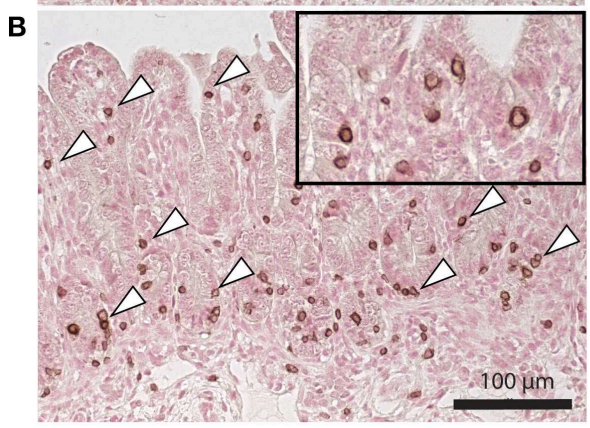

C

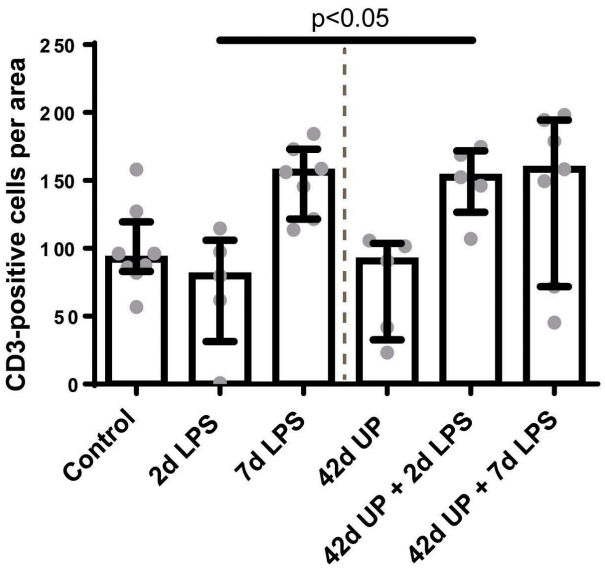

FIGURE 4 | Representative images of mucosal T cell influx reflected by CD3-positive cell (indicated by white triangles) counts of the control (A) and Ureaplasma parvum (UP) prior to 2 days lipopolysaccharide (LPS) (B). (C) Increased CD3 count in animals exposed to UP prior to 2 days LPS compared to the 2 days LPS group.
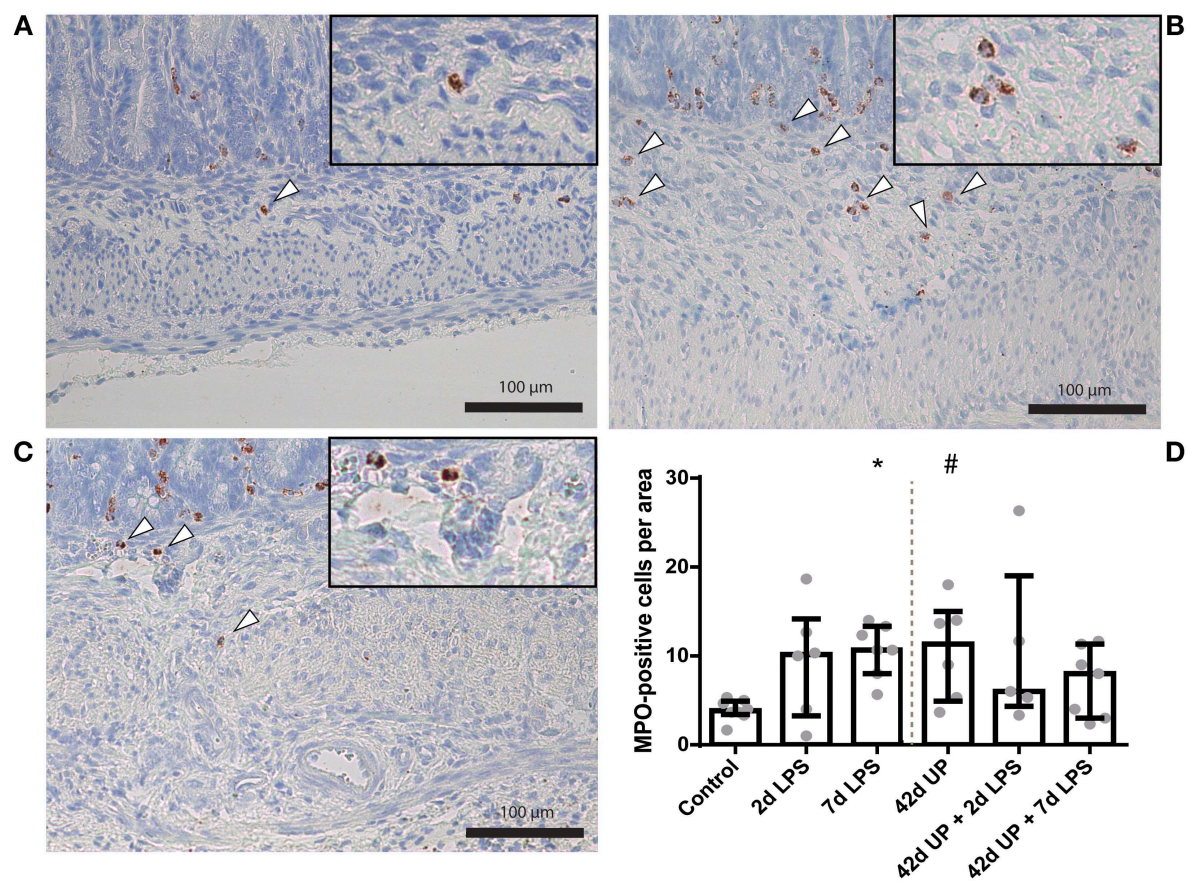

FIGURE 5 | Representative images of submucosal neutrophil influx reflected by myeloperoxidase (MPO)-positive cell (indicated by white triangles) counts of the control (A), 7 days lipopolysaccharide (LPS) (B) and Ureaplasma parvum (UP) (C). (D) Increased MPO count in animals exposed to 7 days LPS and UP. \# $p=0.06$, ${ }^{*} p<0.05$ compared to the control.

LPS exposure on intestinal $I L-1 \beta$ mRNA levels was found in the current study. This is supported by our IRAK3 mRNA findings, a negative regulator of TLR signaling (35), which remained unaltered in combined exposure of UP-infected animals to LPS. Based on these joined findings, it is tempting to speculate that UP + LPS induced the upregulation of cell adhesion molecules 


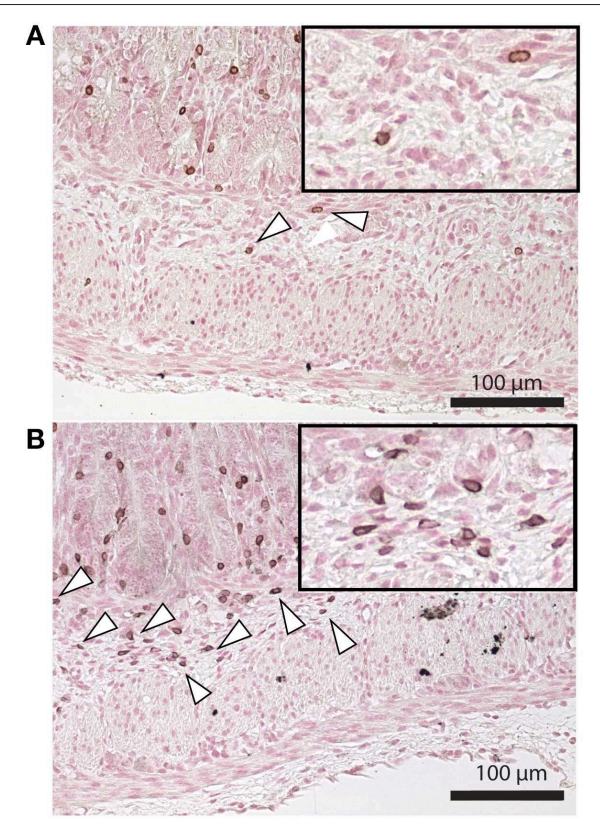

C

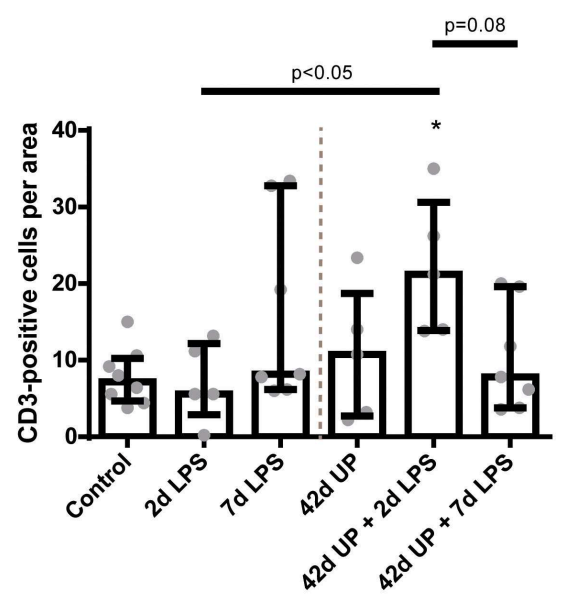

FIGURE 6 | Representative images of submucosal T cell influx reflected by CD3-positive cell (indicated by white triangles) counts of the control (A) and Ureaplasma parvum (UP) prior to 2 days lipopolysaccharide (LPS) groups (B). (C) Increased CD3 count in animals exposed to UP prior to 2 days LPS. ${ }^{*} p<0.05$ compared to the control.

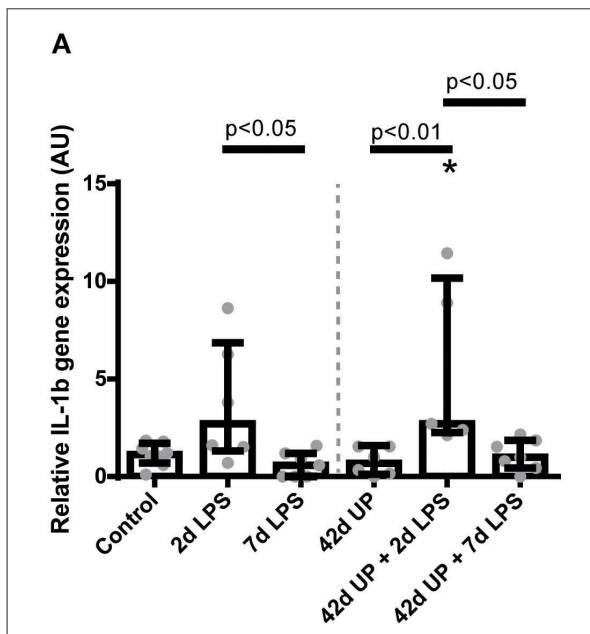

B

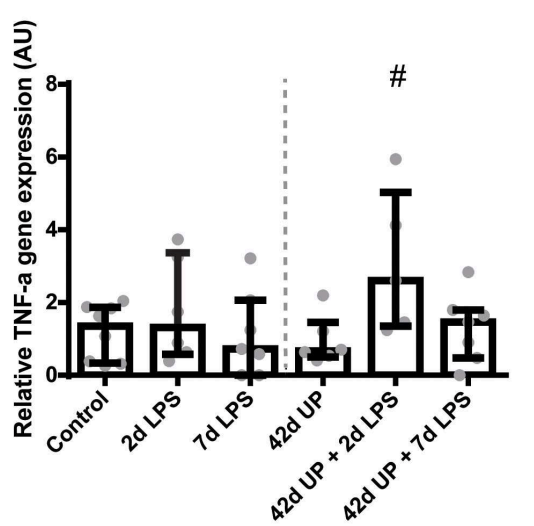

C

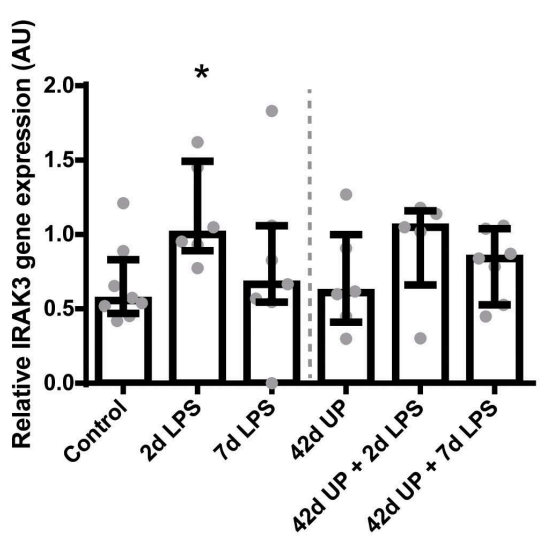

FIGURE 7 | Relative mRNA levels of $I L-1 \beta$ (A), TNF- $\alpha$ (B), and IRAK3 (C) in arbitrary unit (AU). (A) Increased $I L-1 \beta$ mRNA level in animals exposed to 2 days lipopolysaccharide (LPS) and Ureaplasma parvum (UP) prior to 2 days LPS. ${ }^{*} p<0.05$ compared to the control. (B) Increased TNF- $\alpha$ mRNA level in animals exposed to UP prior to 2 days LPS. ${ }^{*} p=0.07$ compared to the control. (C) Increased IRAK3 mRNA level in animals exposed to 2 days LPS. ${ }^{*} p<0.05$ compared to the control.

and, consequently, temporarily increased diapedesis, which could at least in part be responsible for the observed increase in CD3positive cells. The latter suggestion is supported by previous in vitro findings showing enhanced endothelial protein expression of the cell adhesion molecule CXCR7 following co-incubation with LPS and UP, which was not observed in independently UPor LPS-exposed cells (36).

Interestingly, other ovine studies have reported a suppressive immune effect in the premature lung and brain after chronic UP exposure prior to acute LPS exposure $(18,19)$. Taken together, these data show that cells might be sensitized, preconditioned, or remain unaffected following chronic UP infection, indicating organ-dependent responses. The mechanisms responsible for organ-specific effects of a second-hit chorioamnionitis remain to be elucidated.

The ENS closely interacts with intestinal immune cells (37). As such, ENS alterations can both result from intestinal inflammation and modulate it $(38,39)$. In this study, the most evident signs of ENS alterations were seen after chronic UP infection, which caused a reduced PGP9.5-positive surface area 


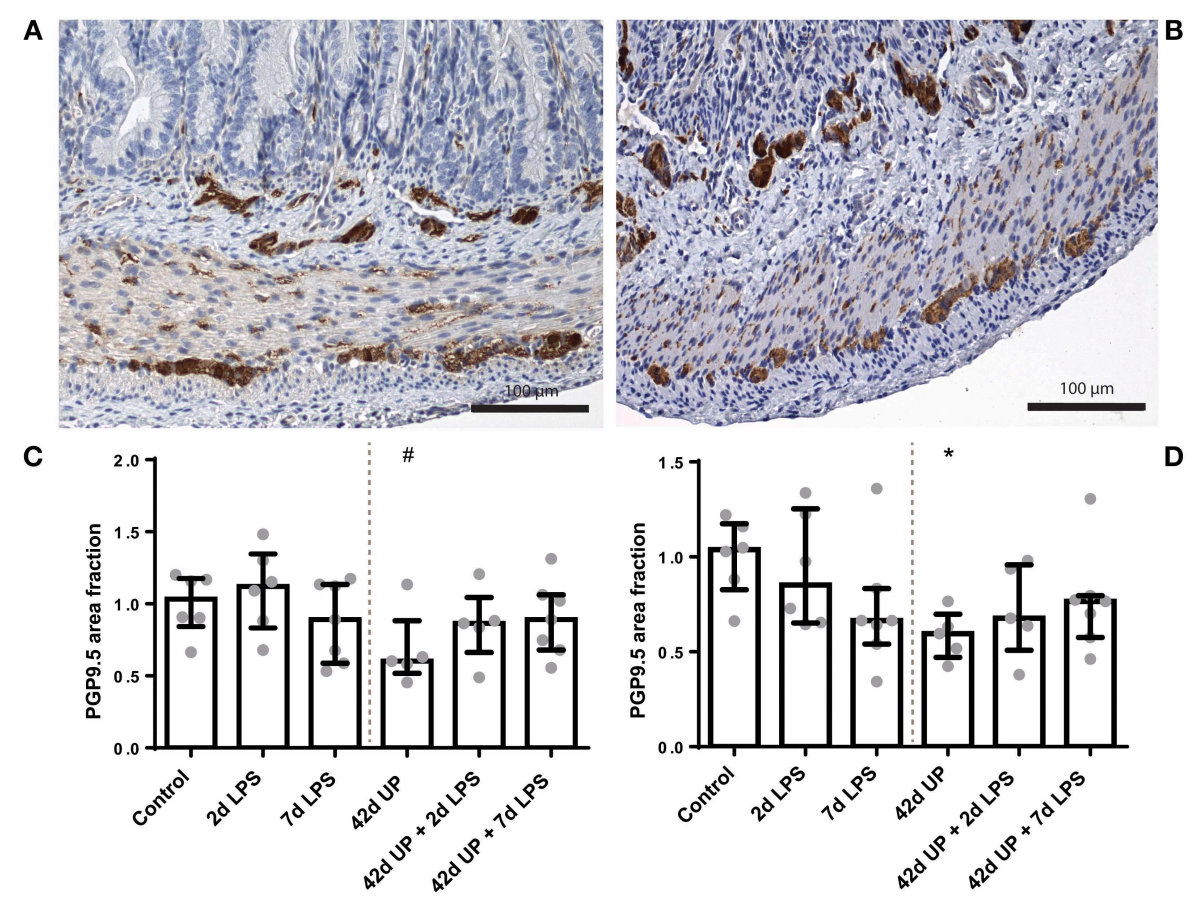

FIGURE 8 | Representative images of PGP9.5 immunoreactivity in the submucosal and myenteric plexus of the control (A) and Ureaplasma parvum (UP) (B) groups. Area fraction of PGP9.5 in the submucosal plexus (C) and myenteric plexus (D) as fold increase over the control value. (C) PGP9.5-positive surface area tended to be decreased in the submucosal plexus of animals exposed to UP. ${ }^{\#} p=0.08$ compared to the control. (D) Decreased PGP9.5-positive surface area in the myenteric plexus of animals exposed to UP. ${ }^{\star} p<0.05$ compared to the control.

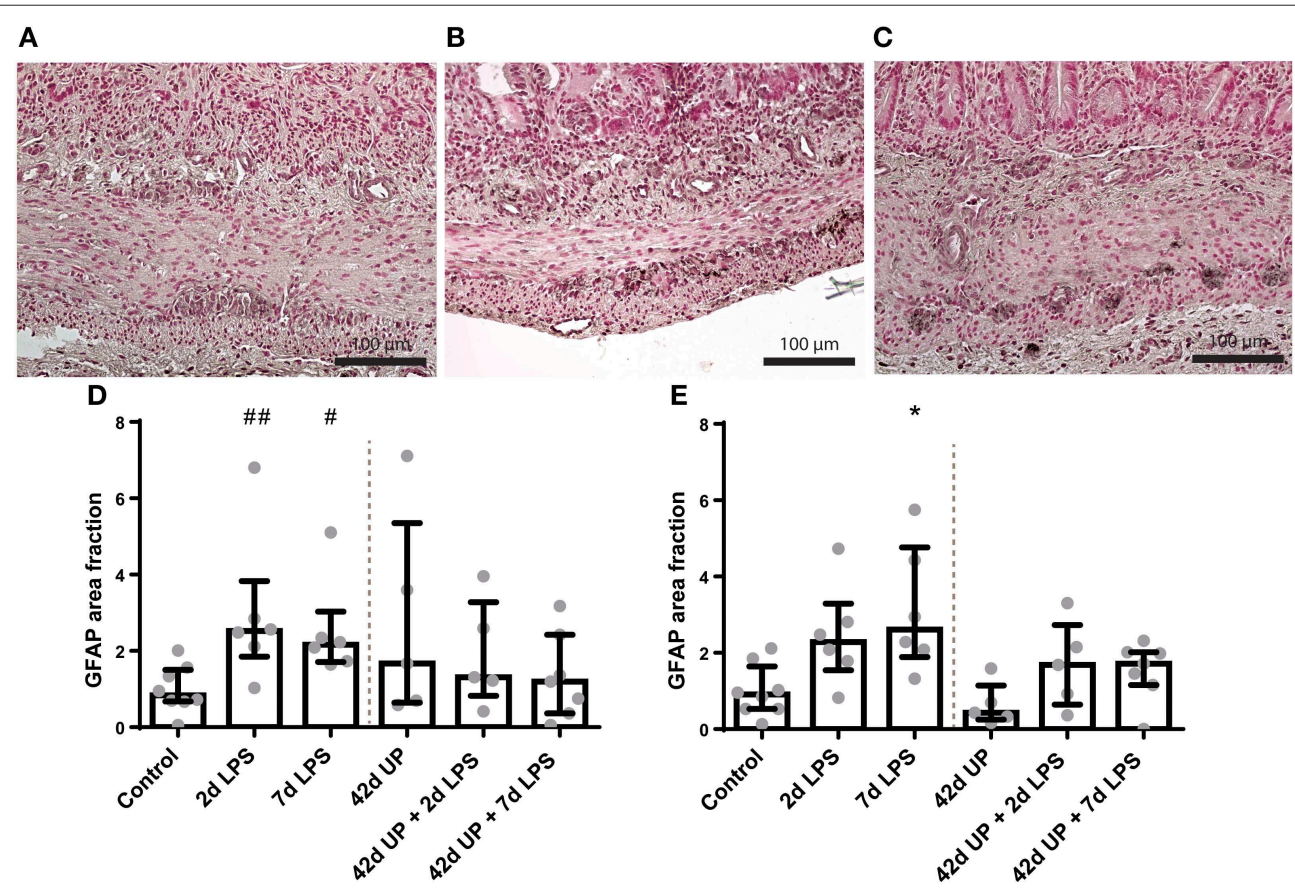

FIGURE 9 | Representative images of glial fibrillary acidic protein (GFAP) immunoreactivity in the submucosal and myenteric plexus of the control (A), 2 days lipopolysaccharide (LPS) (B), and 7 days LPS (C) group. Area fraction of GFAP in the submucosal plexus (D) and myenteric plexus (E) as fold increase over the control value. (D) The GFAP-positive surface area tended to be increased in the submucosal plexus of animals exposed to $2-$ and 7 days LPS. $\# \# p=0.07$, $\# p=0.09$ compared to the control. (E) Increased GFAP-positive surface area in the myenteric plexus of animals exposed to 7 days LPS. ${ }^{*} p<0.05$ compared to the control. 

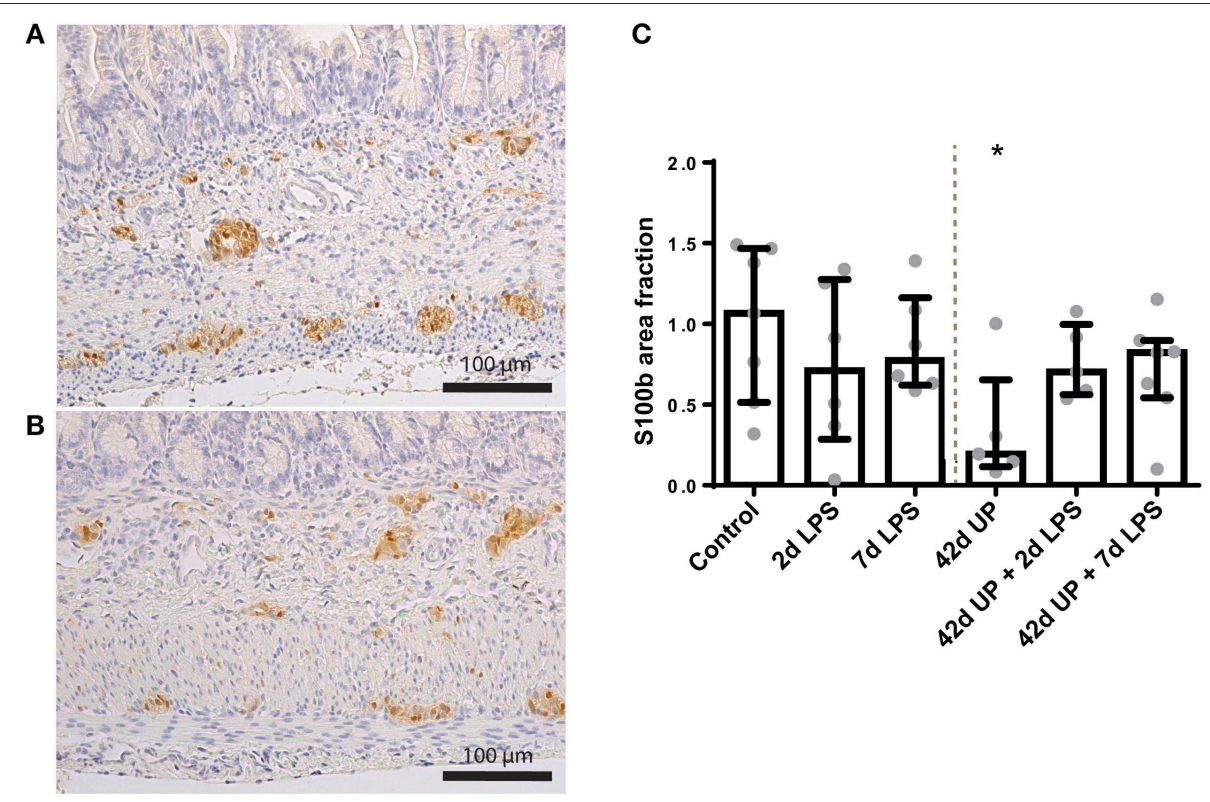

FIGURE 10 | Representative images of S100 $\beta$ immunoreactivity in the submucosal and myenteric plexus of the control (A) and Ureaplasma parvum (UP) group (B). Area fraction of $\mathrm{S} 100 \beta$ in the myenteric plexus (C) as fold increase over the control value. (C) The S100 $\beta$-positive surface area was decreased in the myenteric plexus of animals exposed to UP. ${ }^{*} p<0.05$ compared to the control.

in both plexuses, likely representing a loss of enteric neurons. Alternatively, this might represent a loss of PGP9.5 positivity by enteric neurons. The doublecortin-positive (immature neurons) surface area in chronically UP-infected animals was unchanged, indicating that a decrease of mature neurons is responsible for the observed neuronal cell loss. As the period between 10 and 18 weeks of gestation is considered to be of paramount importance for both morphological and functional maturation of the ENS (40,41), one might assume that the timing of our inflammatory challenge during this vulnerable second trimester is the key determinant for the observed effects rather than the nature of the microbial trigger. The loss of enteric neurons in the myenteric plexus following chronic UP infection coincides with a reduced $S 100 \beta$-positive surface area, suggesting a reduced number of enteric glial cells. However, a reduction of $\mathrm{S} 100 \beta$ immunoreactivity within glial cells could be involved in the observed effect as well. Enteric glial cells are known to contribute to neuronal maintenance, survival, and function (42). Interestingly, the S100 $\beta$-positive surface area was less reduced in the groups exposed to an additional LPS challenge in combination with chronic UP infection, and the median of the PGP9.5-positive surface area was higher in these groups. In support, previous studies have shown that enteric glial cells are capable of generating enteric neurons in response to injury $(43,44)$, indicating that glial cells could be the driving cells behind the loss or gain of neurons in our model. As a hallmark of their high level of cellular plasticity (45), enteric glia can respond to inflammatory cues and ENS damage by alternating their morphology and the expression of key proteins such as GFAP, in a process similar to reactive astrogliosis $(46,47)$. In this study, GFAP immunoreactivity was increased in both plexuses in the LPS-exposed animals, indicating that a glial response is induced by intestinal inflammation (48). An enteric glial cell response was not detected in chronic UP-infected animals despite signs of intestinal inflammation, suggesting normalization of the GFAP levels within this period. Interestingly, pre-conditioning through chronic UP infection prevented GFAP upregulation in response to the overlapping second challenge with LPS in the glial cells in both plexuses, as no altered GFAP immunoreactivity was seen following subsequent IA LPS exposure. Whether this is solely protective or can contribute to the ENS damage seen in chronic UP exposure is unclear, as activation of enteric glia in the context of intestinal inflammation has been described to be both destructive (49) and potentially neuroregenerative (50). We may conclude from the aforementioned findings that enteric glial cells are already able to react to inflammatory cues prenatally. Importantly, our results suggest that these cells play an important role in neuronal survival and neurogenesis in the intrauterine setting.

At present, the postnatal consequences of the detected loss of mature neurons and glial cells following UP exposure in the second trimester remain unknown. A similar decrease in enteric neurons has been described in models of experimental colitis, which show that neuronal loss persists after recovery of inflammation (51) and is accompanied by a decreased colonic motility (52). Based on these combined findings, it is likely that the observed changes in utero will result in ENS dysfunction postnatally.

Interestingly, several studies describe intestinal changes in patients with acute NEC that are similar to those found after chronic UP infection, namely, loss of both enteric neurons $(25-27,53)$ and glial cells $(25-27)$. Moreover, it has been suggested that ablation of enteric glial cells may be an upstream target of NEC pathology (54). A potential causal role of the 
ENS in NEC pathophysiology is further supported by a rat study in which increased NEC survival and intestinal motility was associated with improvement of ENS changes, including an increase in enteric neurons (27). Collectively, our findings form a novel mechanistic explanation for the reported association of chorioamnionitis and NEC.

A limitation of this study is that it only enables us to study the effects of UP and LPS exposure at one time point, preventing us from dissecting the role of the different inflammatory triggers (LPS and UP) of inflammation duration (acute and chronic). In addition, the group sizes are small, which is an inherent shortcoming of the translational ovine model used.

In summary, an acute inflammatory stimulus with LPS or a chronic inflammatory stimulus with UP causes intestinal injury and inflammation in the mucosal and submucosal layers of the gut. Combined overlapping microbial exposure does not aggravate injury of the terminal ileum. Most importantly, chronic UP infection causes structural ENS alterations characterized by PGP9.5 and S100 $\beta$ immunoreactivity loss. Whether the observed ENS alterations result in functional abnormalities after birth remains to be elucidated. However, the observed changes in utero correspond with findings in neonates with NEC, which underlines the concept that NEC pathophysiology may already have its origin in utero.

\section{DATA AVAILABILITY STATEMENT}

The datasets generated for this study are available on request to the corresponding author.

\section{REFERENCES}

1. Murphy SL, Mathews TJ, Martin JA, Minkovitz CS, Strobino DM. Annual Summary of Vital Statistics: 2013-2014. Pediatrics. (2017) 139:e20163239. doi: 10.1542/peds.2016-3239

2. Howson CP, Kinney MV, McDougall L, Lawn JE, Born Too Soon Preterm Birth Action Group. Born too soon: preterm birth matters. Reprod Health. (2013) 10(Suppl. 1):S1. doi: 10.1186/1742-475510-S1-S1

3. Blencowe $\mathrm{H}$, Cousens $\mathrm{S}$. Addressing the challenge of neonatal mortality. Trop Med Int Health. (2013) 18:303-12. doi: 10.1111/tm i. 12048

4. Blencowe H, Cousens S, Oestergaard MZ, Chou D, Moller AB, Narwal $\mathrm{R}$, et al. National, regional, and worldwide estimates of preterm birth rates in the year 2010 with time trends since 1990 for selected countries: a systematic analysis and implications. Lancet. (2012) 379:2162-72. doi: 10.1016/S0140-6736(12)60820-4

5. Galinsky R, Polglase GR, Hooper SB, Black MJ, Moss TJ. The consequences of chorioamnionitis: preterm birth and effects on development. J Pregnancy. (2013) 2013:412831. doi: 10.1155/2013/412831

6. Goldenberg RL, Hauth JC, Andrews WW. Intrauterine infection and preterm delivery. $N$ Engl $J$ Med. (2000) 342:1500-7. doi: 10.1056/NEJM200005183422007

7. Tita AT, Andrews WW. Diagnosis and management of clinical chorioamnionitis. Clin Perinatol. (2010) 37:339-54. doi: 10.1016/j.clp.2010.02.003

8. Peng CC, Chang JH, Lin HY, Cheng PJ, Su BH. Intrauterine inflammation, infection, or both (Triple I): A new concept for chorioamnionitis.

\section{ETHICS STATEMENT}

The animal study was reviewed and approved by The Animal Ethics Committee of the University of Western Australia (Perth, Australia).

\section{AUTHOR CONTRIBUTIONS}

$\mathrm{CH}$, IL, MH, WG, and TW conceived the original idea. MS, $\mathrm{HU}, \mathrm{SS}, \mathrm{OS}, \mathrm{MB}, \mathrm{MP}, \mathrm{JN}, \mathrm{AJ}$, and $\mathrm{MK}$ designed the in vivo model and performed the animal experiments. $\mathrm{CH}$ carried out the laboratory analyses with the support from NR, LK, and GR. $\mathrm{CH}, \mathrm{IL}, \mathrm{MH}, \mathrm{KL}, \mathrm{VM}, \mathrm{WB}, \mathrm{BK}, \mathrm{WG}$, and TW contributed to the interpretation of the results. $\mathrm{CH}$ and IL wrote the manuscript with the input from all authors. WG and TW supervised the project. All authors contributed to manuscript revision, read, and approved the submitted version.

\section{FUNDING}

This work was supported by the National Institutes of Health (Bethesda, MD, USA) grant (HD 57869) and the Kinderonderzoekfonds Limburg (TW).

\section{ACKNOWLEDGMENTS}

The authors would like to thank Ellen Oostenbach for her excellent technical assistance.
Pediatr Neonatol. (2018) 59:231-7. doi: 10.1016/j.pedneo.201 7.09.001

9. Silwedel C, Speer CP, Glaser K. Ureaplasma-associated prenatal, perinatal, and neonatal morbidities. Expert Rev Clin Immunol. (2017) 13:1073-87. doi: 10.1080/1744666X.2017.1381559

10. Viscardi RM. Ureaplasma species: role in diseases of prematurity. Clin Perinatol. (2010) 37:393-409. doi: 10.1016/j.clp.200 9.12 .003

11. Been JV, Lievense S, Zimmermann LJ, Kramer BW, Wolfs TG. Chorioamnionitis as a risk factor for necrotizing enterocolitis: a systematic review and meta-analysis. J Pediatr. (2013) 162:236-42.e2. doi: 10.1016/j.jpeds.2012.07.012

12. Okogbule-Wonodi AC, Gross GW, Sun CC, Agthe AG, Xiao L, Waites $\mathrm{KB}$, et al. Necrotizing enterocolitis is associated with ureaplasma colonization in preterm infants. Pediatr Res. (2011) 69(5 Pt 1):442-7. doi: 10.1203/PDR.0b013e3182111827

13. Wolfs TG, Jellema RK, Turrisi G, Becucci E, Buonocore G, Kramer BW. Inflammation-induced immune suppression of the fetus: a potential link between chorioamnionitis and postnatal early onset sepsis. J Matern Fetal Neonatal Med. (2012) 25(Suppl. 1):8-11. doi: 10.3109/14767058.2012.66 4447

14. Wolfs TG, Kramer BW, Thuijls G, Kemp MW, Saito M, Willems MG, et al. Chorioamnionitis-induced fetal gut injury is mediated by direct gut exposure of inflammatory mediators or by lung inflammation. Am J Physiol Gastrointest Liver Physiol. (2014) 306:G382-93. doi: 10.1152/ajpgi.0026 0.2013

15. Kataoka S, Yamada T, Chou K, Nishida R, Morikawa M, Minami $\mathrm{M}$, et al. Association between preterm birth and vaginal colonization 
by mycoplasmas in early pregnancy. J Clin Microbiol. (2006) 44:51-5. doi: 10.1128/JCM.44.1.51-55.2006

16. Sweeney EL, Dando SJ, Kallapur SG, Knox CL. The human ureaplasma species as causative agents of chorioamnionitis. Clin Microbiol Rev. (2017) 30:349-79. doi: 10.1128/CMR.00091-16

17. Wolfs TG, Kallapur SG, Knox CL, Thuijls G, Nitsos I, Polglase GR, et al. Antenatal ureaplasma infection impairs development of the fetal ovine gut in an IL-1-dependent manner. Mucosal Immunol. (2013) 6:547-56. doi: $10.1038 / \mathrm{mi} .2012 .97$

18. Gussenhoven R, Ophelders DRMG, Kemp MW, Payne MS, Spiller OB, Beeton ML, et al. The paradoxical effects of chronic intra-amniotic Ureaplasma parvum exposure on ovine fetal brain development. Dev Neurosci. (2017) 39:472-86. doi: 10.1159/000479021

19. Kallapur SG, Kramer BW, Knox CL, Berry CA, Collins JJ, Kemp MW, et al. Chronic fetal exposure to Ureaplasma parvum suppresses innate immune responses in sheep. J Immunol. (2011) 187:2688-95. doi: 10.4049/jimmunol.1100779

20. Furness JB. The Enteric Nervous System. Oxford: Blackwell Publishing (2006). doi: $10.1002 / 9780470988756$

21. Lake JI, Heuckeroth RO. Enteric nervous system development: migration, differentiation, and disease. Am J Physiol Gastrointest Liver Physiol. (2013) 305:G1-24. doi: 10.1152/ajpgi.00452.2012

22. Rao M, Gershon MD. Enteric nervous system development: what could possibly go wrong? Nat Rev Neurosci. (2018) 19:552-65. doi: 10.1038/s41583-018-0041-0

23. Burns AJ, Roberts RR, Bornstein JC, Young HM. Development of the enteric nervous system and its role in intestinal motility during fetal and early postnatal stages. Semin Pediatr Surg. (2009) 18:196-205. doi: 10.1053/j.sempedsurg.2009.07.001

24. Hao MM, Foong JP, Bornstein JC, Li ZL, Vanden Berghe P, Boesmans W. Enteric nervous system assembly: functional integration within the developing gut. Dev Biol. (2016) 417:168-81. doi: 10.1016/j.ydbio.201 6.05 .030

25. Sigge W, Wedel T, Kuhnel W, Krammer HJ. Morphologic alterations of the enteric nervous system and deficiency of non-adrenergic non-cholinergic inhibitory innervation in neonatal necrotizing enterocolitis. Eur J Pediatr Surg. (1998) 8:87-94. doi: 10.1055/s-2008-1071128

26. Wedel T, Krammer HJ, Kuhnel W, Sigge W. Alterations of the enteric nervous system in neonatal necrotizing enterocolitis revealed by wholemount immunohistochemistry. Pediatr Pathol Lab Med. (1998) 18:57-70. doi: 10.1080/107710498174227

27. Zhou Y, Yang J, Watkins DJ, Boomer LA, Matthews MA, Su Y, et al. Enteric nervous system abnormalities are present in human necrotizing enterocolitis: potential neurotransplantation therapy. Stem Cell Res Ther. (2013) 4:157. doi: $10.1186 /$ scrt387

28. Moss TJ, Knox CL, Kallapur SG, Nitsos I, Theodoropoulos C, Newnham JP, et al. Experimental amniotic fluid infection in sheep: effects of Ureaplasma parvum serovars 3 and 6 on preterm or term fetal sheep. Am J Obstet Gynecol. (2008) 198:122.e1-8. doi: 10.1016/j.ajog.2007.06.065

29. Kramer BW, Moss TJ, Willet KE, Newnham JP, Sly PD, Kallapur SG, et al. Dose and time response after intraamniotic endotoxin in preterm lambs. Am J Respir Crit Care Med. (2001) 164:982-8. doi: 10.1164/ajrccm.164.6.2 103061

30. Newnham JP, Kallapur SG, Kramer BW, Moss TJ, Nitsos I, Ikegami $\mathrm{M}$, et al. Betamethasone effects on chorioamnionitis induced by intraamniotic endotoxin in sheep. Am J Obstet Gynecol. (2003) 189:1458-66. doi: 10.1067/S0002-9378(03)00758-0

31. Miura Y, Payne MS, Keelan JA, Noe A, Carter S, Watts R, et al. Maternal intravenous treatment with either azithromycin or solithromycin clears Ureaplasma parvum from the amniotic fluid in an ovine model of intrauterine infection. Antimicrob Agents Chemother. (2014) 58:5413-20. doi: 10.1128/AAC.03187-14

32. Rao M, Nelms BD, Dong L, Salinas-Rios V, Rutlin M, Gershon MD, et al. Enteric glia express proteolipid protein 1 and are a transcriptionally unique population of glia in the mammalian nervous system. Glia. (2015) 63:2040-57. doi: $10.1002 /$ glia.22876

33. Manimtim WM, Hasday JD, Hester L, Fairchild KD, Lovchik JC, Viscardi RM. Ureaplasma urealyticum modulates endotoxin-induced cytokine release by human monocytes derived from preterm and term newborns and adults. Infect Immun. (2001) 69:3906-15. doi: 10.1128/IAI.69.6.3906-391 5.2001

34. Shimizu T, Kida Y, Kuwano K. Ureaplasma parvum lipoproteins, including MB antigen, activate NF-\{kappa\}B through TLR1, TLR2 and TLR6. Microbiology. (2008) 154(Pt 5):1318-25. doi: 10.1099/mic.0.2007/01 $6212-0$

35. Kobayashi K, Hernandez LD, Galan JE, Janeway CA Jr, Medzhitov R, Flavell RA. IRAK-M is a negative regulator of Toll-like receptor signaling. Cell. (2002) 110:191-202. doi: 10.1016/S0092-8674(02)0 0827-9

36. Silwedel C, Speer CP, Haarmann A, Fehrholz M, Claus H, Buttmann M, et al. Novel insights into neuroinflammation: bacterial lipopolysaccharide, tumor necrosis factor $\alpha$, and Ureaplasma species differentially modulate atypical chemokine receptor 3 responses in human brain microvascular endothelial cells. J Neuroinflammation. (2018) 15:156. doi: 10.1186/s12974-0181170-0

37. Yoo BB, Mazmanian SK. The enteric network: interactions between the immune and nervous systems of the gut. Immunity. (2017) 46:910-26. doi: 10.1016/j.immuni.2017.05.011

38. Brierley SM, Linden DR. Neuroplasticity and dysfunction after gastrointestinal inflammation. Nat Rev Gastroenterol Hepatol. (2014) 11:611-27. doi: 10.1038/nrgastro.2014.103

39. Margolis KG, Gershon MD. Enteric neuronal regulation of intestinal inflammation. Trends Neurosci. (2016) 39:614-24. doi: 10.1016/j.tins.2016.06.007

40. Fekete E, Resch BA, Benedeczky I. Histochemical and ultrastructural features of the developing enteric nervous system of the human foetal small intestine. Histol Histopathol. (1995) 10:127-34.

41. Fekete E, Bagyánszki M, Resch BA. Prenatal development of the myenteric plexus in the human fetal small intestine. Acta Biol Szeged. (2000) 44:3-19.

42. De Giorgio R, Giancola F, Boschetti E, Abdo H, Lardeux B, Neunlist M. Enteric glia and neuroprotection: basic and clinical aspects. Am J Physiol Gastrointest Liver Physiol. (2012) 303:G887-93. doi: 10.1152/ajpgi.0009 6.2012

43. Joseph NM, He S, Quintana E, Kim YG, Nunez G, Morrison SJ. Enteric glia are multipotent in culture but primarily form glia in the adult rodent gut. J Clin Invest. (2011) 121:3398-411. doi: 10.1172/JCI 58186

44. Laranjeira C, Sandgren K, Kessaris N, Richardson W, Potocnik A, Vanden Berghe P, et al. Glial cells in the mouse enteric nervous system can undergo neurogenesis in response to injury. J Clin Invest. (2011) 121:3412-24. doi: $10.1172 /$ JCI58200

45. Boesmans W, Lasrado R, Vanden Berghe P, Pachnis V. Heterogeneity and phenotypic plasticity of glial cells in the mammalian enteric nervous system. Glia. (2015) 63:229-41. doi: 10.1002/glia.22746

46. Chow AK, Gulbransen BD. Potential roles of enteric glia in bridging neuroimmune communication in the gut. Am J Physiol Gastrointest Liver Physiol. (2017) 312:G145-52. doi: 10.1152/ajpgi.0038 4.2016

47. Rosenbaum C, Schick MA, Wollborn J, Heider A, Scholz CJ, Cecil A, et al. Activation of myenteric glia during acute inflammation in vitro and in vivo. PLoS ONE. (2016) 11:e0151335. doi: 10.1371/journal.pone.01 51335

48. Cirillo C, Sarnelli G, Turco F, Mango A, Grosso M, Aprea $\mathrm{G}$, et al. Proinflammatory stimuli activates human-derived enteroglial cells and induces autocrine nitric oxide production. Neurogastroenterol Motil. (2011) 23:e372-82. doi: 10.1111/j.1365-2982.2011.0 1748. $\mathrm{x}$

49. Brown IA, McClain JL, Watson RE, Patel BA, Gulbransen BD. Enteric glia mediate neuron death in colitis through purinergic pathways that require connexin-43 and nitric oxide. Cell Mol Gastroenterol Hepatol. (2016) 2:77-91. doi: 10.1016/j.jcmgh.2015.08.007

50. Belkind-Gerson J, Graham HK, Reynolds J, Hotta R, Nagy N, Cheng $\mathrm{L}$, et al. Colitis promotes neuronal differentiation of Sox $2+$ and PLP1+ enteric cells. Sci Rep. (2017) 7:2525. doi: 10.1038/s41598-017-0 $2890-\mathrm{y}$ 
51. Linden DR, Couvrette JM, Ciolino A, McQuoid C, Blaszyk H, Sharkey $\mathrm{KA}$, et al. Indiscriminate loss of myenteric neurones in the TNBSinflamed guinea-pig distal colon. Neurogastroenterol Motil. (2005) 17:751-60. doi: 10.1111/j.1365-2982.2005.00703.x

52. Boyer L, Ghoreishi M, Templeman V, Vallance BA, Buchan AM, Jevon G, et al. Myenteric plexus injury and apoptosis in experimental colitis. Auton Neurosci. (2005) 117:41-53. doi: 10.1016/j.autneu.200 4.10 .006

53. Fagbemi AO, Torrente F, Puleston J, Lakhoo K, James S, Murch $\mathrm{SH}$. Enteric neural disruption in necrotizing enterocolitis occurs in association with myenteric glial cell CCL20 expression. J Pediatr Gastroenterol Nutr. (2013) 57:788-93. doi: 10.1097/MPG.0b013e3182a $86 \mathrm{fd} 4$

54. Bush TG. Enteric glial cells. An upstream target for induction of necrotizing enterocolitis and Crohn's disease? Bioessays. (2002) 24:130-40. doi: 10.1002/bies.10039
Conflict of Interest: The authors declare that the research was conducted in the absence of any commercial or financial relationships that could be construed as a potential conflict of interest.

The handling editor declared a past co-authorship with several of the authors TW, BK.

Copyright (c) 2020 Heymans, de Lange, Hütten, Lenaerts, de Ruijter, Kessels, Rademakers, Melotte, Boesmans, Saito, Usuda, Stock, Spiller, Beeton, Payne, Kramer, Newnham, Jobe, Kemp, van Gemert and Wolfs. This is an open-access article distributed under the terms of the Creative Commons Attribution License (CC BY). The use, distribution or reproduction in other forums is permitted, provided the original author(s) and the copyright owner(s) are credited and that the original publication in this journal is cited, in accordance with accepted academic practice. No use, distribution or reproduction is permitted which does not comply with these terms. 